\title{
Cisto linfoepitelial oral: relato de quatro casos e revisão de 119 casos apresentados na literatura
}

Primeira submissão em 14/05/09 Última submissão em 26/10/09 Aceito para publicação em 04/02/10 Publicado em 20/04/10

\section{Oral lymphoepithelial cyst: report of 4 cases and review of 119 cases reported in the literature}

Luiz Eduardo Rodrigues Juliasse'; Ana Carolina Meneses Resende²; Alexandre Pinto Maia ${ }^{3}$; Cassiano Francisco Weege Nonaka ${ }^{4}$; Hébel Cavalcanti Galvão ${ }^{5}$; Leão Pereira Pinto ${ }^{6}$

unitermos
Cisto linfoepitelial
Boca
Histopatologia
Diagnóstico
diferencial

resumo

Introdução: O cisto linfoepitelial oral é uma lesão incomum, assintomática e de pequenas dimensões, geralmente descoberto durante exames de rotina da cavidade bucal. Objetivo: Relatar quatro casos de cisto linfoepitelial oral, confrontando seus aspectos com aqueles reportados em outros 119 casos publicados na literatura. Relato dos casos: Três casos em mulheres, com idade entre 16 e 23 anos, e um caso em homem, com 45 anos, caracterizados por nódulos assintomáticos, de pequenas dimensões e coloração variando do branco ao amarelado. Dois casos estavam localizados na superfície ventral da língua, um em assoalho bucal e outro em orofaringe. Histologicamente, as lesões revelaram cavidade cística contendo quantidade variável de células epiteliais descamadas, revestida por epitélio pavimentoso estratificado, predominantemente paraceratinizado, de interface plana com o tecido conjuntivo. A cápsula fibrosa exibiu um denso infiltrado linfocítico, com identificação de centros germinativos em apenas dois casos. Conclusão: A análise conjunta dos casos apresentados neste trabalho e de outros 119 casos relatados na literatura revela que os cistos linfoepiteliais orais exibem predileção pelo gênero masculino, com ápice de incidência na terceira década de vida. Em geral, essas lesões se apresentam como pequenos nódulos assintomáticos localizados no assoalho bucal. Histologicamente, a maioria dos casos revela epitélio cístico com padrão de maturação paraceratinizado e exibe centros germinativos na cápsula fibrosa.

abstract

Introduction: The oral lymphoepithelial cyst is a rare, asymptomatic lesion with small dimensions, commonly discovered during routine examination of the oral cavity. Objective: To report four cases of oral lymphoepithelial cyst and compare their aspects with other 119 cases reported in the literature. Case report: Three cases in women, age range 16 to 23, and one case in a 45-year-old man, all of them presenting small, asymptomatic, yellowish-white nodules. Two cases were located in the ventral surface of the tongue, one in the buccal floor and one in the oropharynx. Histologically, the lesions showed cystic cavity with variable amount of desquamated epithelial cells, lined with a parakeratinized stratified squamous epithelium and a plane interface with the connective tissue. The fibrous capsule showed a dense lymphocyte infiltrate with germinal centers in only two cases. Conclusion: The analysis of the cases herein and the other 119 cases reported in the literature reveals that oral lymphoepithelial cysts present a predilection for males, with peak of incidence in the third decade of life. Characteristically, these lesions consist of small asymptomatic nodules located in the buccal floor. Histologically, most cases show a parakeratinized epithelial lining and germinal centers in the fibrous capsule.

\section{key words}

Lymphoepithelial cyst

Oral cavity

Histopathology

Differential diagnosis

1. Bolsista de iniciação científica do Conselho Nacional de Desenvolvimento Científico e Tecnológico (PIBIC/CNPq) em Patologia Oral pela Universidade Federal do Rio Grande do Norte (UFRN). 2. Bolsista de iniciação científica do PIBIC/CNPq, base de pesquisa da Liga Norte-Rio-Grandense Contra o Câncer (LNRCC), pela UFRN.

3. Doutorando do programa de pós-graduação em Patologia Oral pela UFRN.

4. Doutorando do programa de pós-graduação em Patologia Oral pela UFRN.

5. Professor doutor do programa de pós-graduação em Patologia Oral pela UFRN.

6. Professor doutor do programa de pós-graduação em Patologia Oral pela UFRN. 


\section{Introdução}

O cisto linfoepitelial oral é uma lesão incomum, cuja patogênese permanece incompletamente elucida$\mathrm{da}^{(1,3,4,7-9,15)}$. De acordo com Knapp ${ }^{(12)}$, os cistos linfoepiteliais orais seriam decorrentes de obstrução na cripta de uma tonsila oral, na qual se acumulariam células epiteliais descamadas e/ou material purulento. A existência, em alguns casos, de contiguidade entre o epitélio cístico e o de revestimento da cavidade bucal ${ }^{(3,4,15,19)}$ fortalece a teoria proposta por Knapp ${ }^{(12)}$.

Em geral, os cistos linfoepiteliais orais são diagnosticados durante a terceira década de vida, havendo uma discreta predileção pelo gênero masculino ${ }^{(3,4,16)}$. As lesões são identificadas com maior frequência em áreas da cavidade bucal que apresentam agregados linfoides $(8,12,13,15)$, como 0 assoalho bucal e as superfícies lateral e ventral da língua ${ }^{(10,}$ $11,14,17)$. Clinicamente, o cisto linfoepitelial oral se apresenta como um nódulo móvel, assintomático, com coloração que varia do róseo ao amarelado ${ }^{(3,4,7-9,15)}$ e diâmetro inferior a $1 \mathrm{~cm}^{(2,4,7-9,15)}$. Em virtude do pequeno tamanho e da ausência de sintomatologia, a maioria dos casos é descoberta durante exames de rotina da cavidade bucal $(4,7-9,15)$.

Ao exame histológico, os cistos linfoepiteliais orais revelam uma cavidade central, com quantidades variadas de células epiteliais descamadas, revestida por epitélio pavimentoso estratificado paraceratinizado, que exibe interface plana com o tecido conjuntivo ${ }^{(1,3,4,7,15,19)}$. Tipicamente, a cápsula fibrosa demonstra um linfocítico denso infiltrado, com formação de centros germinativos ${ }^{(1,3,4,7,9,15,19)}$. A excisão cirúrgica conservadora é o tratamento de escolha, não havendo relatos de recidiva ou transformação neoplásica ${ }^{(3,7-9,15)}$.

O presente artigo relata quatro casos de cisto linfoepitelial oral diagnosticados no Serviço de Anatomia Patológica (SAP) da disciplina de Patologia Oral da Universidade Federal do Rio Grande do Norte (UFRN) e realiza uma revisão de outros 119 casos publicados na literatura. Dessa forma, espera-se contribuir para o conhecimento dos aspectos clínicopatológicos dessa lesão.

\section{Relato de casos}

\section{- Caso 1}

Paciente do sexo feminino, 23 anos, foi encaminhada para a avaliação de uma lesão exofítica, esbranquiçada, de consistência amolecida, localizada na superfície ventral da língua. A lesão era assintomática, media $1 \mathrm{~cm} \times 0,5 \mathrm{~cm}$ em seus maiores diâmetros e não foi percebida anteriormente pela paciente, sendo identificada durante um exame de rotina da cavidade bucal. Sob hipótese clínica de cisto epidermoide, foi realizada biópsia excisional, em que se constatou drenagem de secreção cremosa branco-amarelada. $\mathrm{O}$ exame microscópico revelou uma cavidade luminal revestida por epitélio pavimentoso estratificado paraceratinizado, com interface plana com o tecido conjuntivo. O lúmen cístico revelava escassas células inflamatórias e células epiteliais descamadas. A cápsula de tecido conjuntivo apresentava intenso infiltrado linfocítico, circunscrevendo parcialmente o revestimento epitelial, sem centros germinativos. A lesão se apresentou bem delimitada, apesar da íntima proximidade com feixes musculares estriados (Figura 1).

\section{- Caso 2}

Paciente do sexo feminino, 17 anos, revelava um nódulo esbranquiçado, assintomático, de consistência fibrosa, com aproximadamente $0,5 \mathrm{~cm}$, localizado no assoalho bucal. A paciente não soube informar o tempo de evolução da lesão. Sob diagnóstico clínico de fibroma, foi realizada biópsia excisional. O exame histopatológico revelou lesão cística revestida por epitélio pavimentoso estratificado paraceratinizado, com interface predominantemente plana com o tecido conjuntivo. O lúmen cístico exibia pequena quantidade de células epiteliais descamadas e a cápsula fibrosa demonstrava intenso infiltrado linfocítico, circunscrevendo completamente o revestimento epitelial, com diversos centros germinativos (Figura 2).

\section{- Caso 3}

Paciente do sexo feminino, 16 anos, apresentou um nódulo amarelado, de superfície lisa e consistência amolecida, na região de orofaringe. O tempo de evolução reportado pela paciente foi de 2 anos, e a lesão revelava $0,5 \mathrm{~cm} \times 0,5 \mathrm{~cm}$ em seus maiores diâmetros. Sob a hipótese diagnóstica de cisto linfoepitelial, procedeu-se biópsia excisional. O exame microscópico revelou cavidade cística revestida por epitélio pavimentoso estratificado, ora não ceratinizado ora paraceratinizado, com interface epitelioconjuntivo plana. O lúmen cístico exibia escassas células inflamatórias e células epiteliais descamadas. A cápsula de tecido conjuntivo demonstrava intenso infiltrado linfocíti$\mathrm{co}$, circunscrevendo parcialmente o revestimento epitelial, sem centros germinativos (Figura 3). 


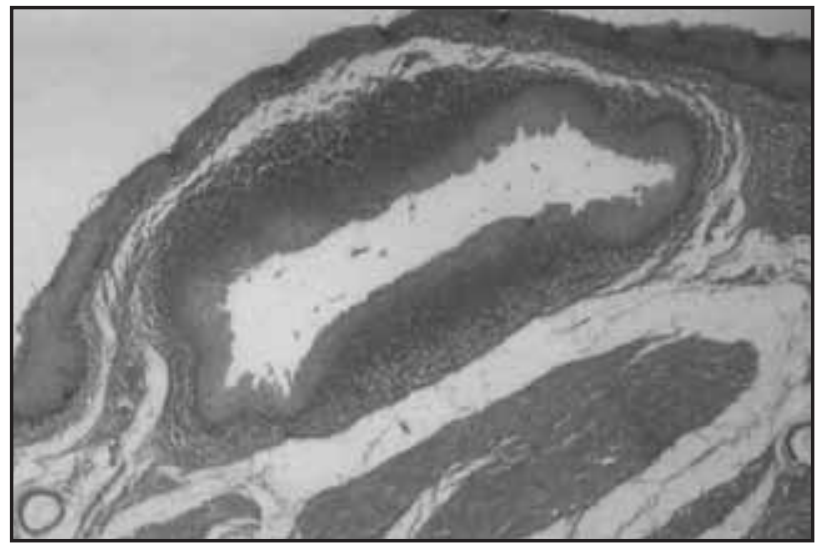

Figura 1 - Fotomicrografia destacando a localização superficial da lesão e o intenso infiltrado linfocítico na cápsula fibrosa (HE, 40x)

HE: hematoxilina e eosina.

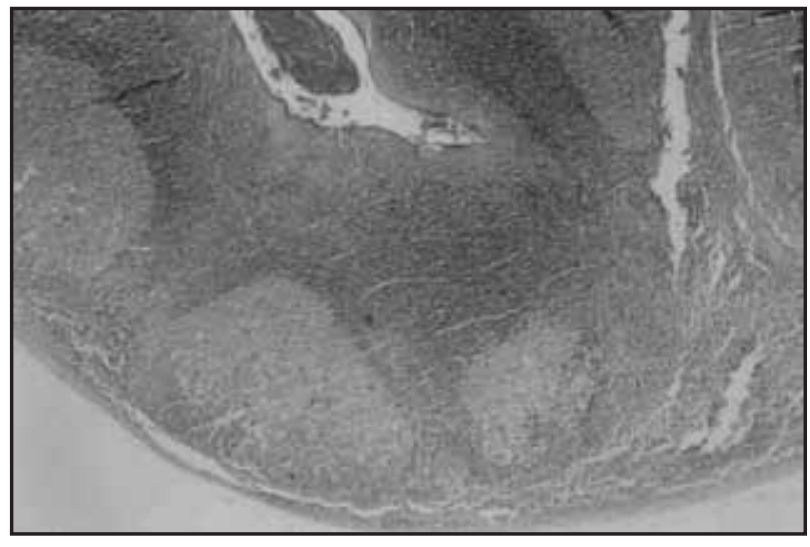

Figura 2 - Fotomicrografia demonstrando a formação de centros germinativos em meio ao intenso infiltrado linfocítico na cápsula fibrosa (HE, 40x) $H E$ : hematoxilina e eosina.

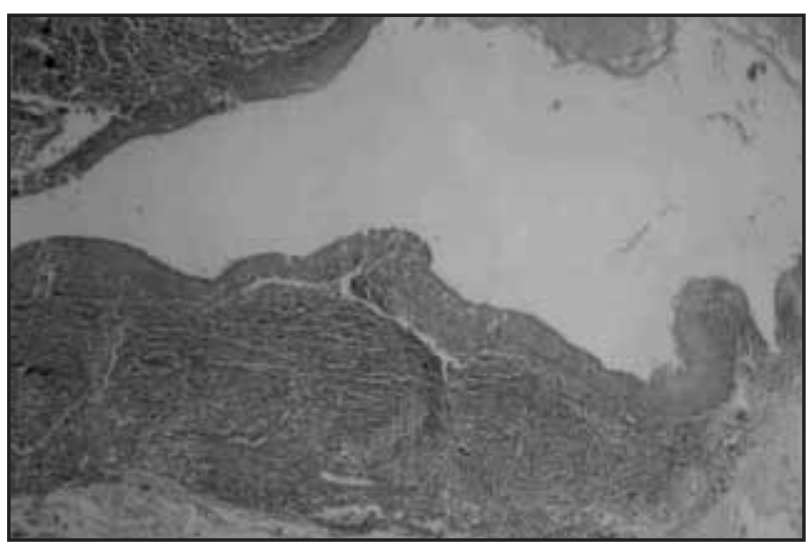

Figura 3 - Fotomicrografia demonstrando cavidade revestida por epitélio pavimentoso estratificado, ora paraceratinizado ora não ceratinizado, com infiltrado linfocítico circunscrevendo parcialmente o revestimento epitelial (HE, 40x) HE: hematoxilina e eosina.

\section{- Caso 4}

Paciente do sexo masculino, 45 anos, apresentava um nódulo branco-amarelado, mole, localizado na superfície ventral da língua. A lesão era bem delimitada, assintomática e media aproximadamente $1 \mathrm{~cm} \times 0,5 \mathrm{~cm}$. O paciente não soube informar o tempo de evolução da lesão. Sob diagnóstico clínico de mucocele, foi realizada biópsia excisional. O exame histopatológico revelou uma cavidade luminal, com pequena quantidade de células epiteliais descamadas, revestida por epitélio pavimentoso estratificado, ora paraceratinizado ora não ceratinizado, com interface plana com o tecido conjuntivo. Na cápsula fibrosa, constatou-se denso infiltrado linfocítico, circunscrevendo parcialmente o revestimento epitelial, com centros germinativos. Apesar da íntima proximidade com feixes musculares estriados, a lesão se apresentou bem delimitada.

\section{Discussão}

Os cistos linfoepiteliais orais são lesões incomuns, constituindo entre $0,09 \%{ }^{(9)}$ e $0,18 \%{ }^{(4)}$ do total de lesões diagnosticadas em Serviços de Patologia Oral. Em consonância com esses achados, os quatro casos apresentados neste trabalho correspondem a $0,04 \%$ dos espécimes mantidos nos arquivos do SAP da disciplina de Patologia Oral da UFRN.

A patogênese dessas lesões ainda não foi completamente esclarecida. De acordo com a clássica teoria de Knapp ${ }^{(12)}$, os cistos linfoepiteliais orais seriam decorrentes de obstrução na cripta de uma tonsila oral, onde se acumulariam células epiteliais descamadas e/ou material purulento. A identificação, em alguns casos, de contiguidade entre o epitélio cístico e o de revestimento da cavidade bucal $(3,4,7,8,15,19)$ fortalece a teoria proposta por Knapp ${ }^{(12)}$. Contudo, mesmo com a realização de cortes seriados, alguns estudos foram incapazes de demonstrar tal relação ${ }^{(1,6,9)}$. Apesar de não terem sido realizados cortes seriados, nenhum dos casos apresentados neste trabalho revelou comunicação entre o epitélio cístico e o de revestimento da cavidade bucal.

Sugere-se, ainda, que os cistos linfoepiteliais orais derivem do aprisionamento de epitélio de revestimento ou do parênquima glandular salivar em meio a agregados linfoides, durante a embriogênese $\mathrm{e}^{(4,8,13,15)}$. Adicionalmente, cita-se a possibilidade dessas lesões terem origem a partir de ductos excretores de glândulas salivares menores e que o infiltrado linfocítico represente apenas resposta imunológica secundária( ${ }^{(4,8)}$.

A análise de 119 casos publicados na literatura (Tabela 1) revela que os cistos linfoepiteliais orais podem acometer indivíduos desde os 4 até os 81 anos de idade. A maioria dos casos (91,3\%) é diagnosticada entre a segunda e sexta décadas de vida, com ápice de incidência na terceira década (31,4\%) (Tabela 2). De forma coerente, três dos quatro casos ora reportados foram diagnosticados entre a segunda e a terceira décadas de vida. Informação sobre o 
Idade, sexo, localização anatômica e tamanho de 119 casos de cisto linfoepitelial oral apresentados Tabela 1 na literatura

\begin{tabular}{|c|c|c|c|c|c|c|}
\hline Autores & $\begin{array}{l}\text { Ano de } \\
\text { publicação }\end{array}$ & $\begin{array}{l}\text { Casos } \\
(n)\end{array}$ & $\begin{array}{l}\text { Idade } \\
\text { (anos) }\end{array}$ & Sexo & Localização anatômica & Tamanho (cm) \\
\hline Gold & 1962 & 1 & 32 & M & Assoalho bucal & \\
\hline Calman & 1963 & 1 & 40 & M & Assoalho bucal & $1 \times 0,6 \times 0,4$ \\
\hline $\begin{array}{l}\text { Vickers } \\
\text { et al. }\end{array}$ & 1963 & 1 & 30 & M & Assoalho bucal & $2 \times 2$ \\
\hline & & & & $17 \mathrm{M}$ & Assoalho bucal $(n=15)$ & \\
\hline Bhaskar & 1966 & 24 & $15-65$ & $7 \mathrm{~F}$ & $\begin{array}{l}\text { Superfície lateral da língua } \\
\qquad(n=8) \\
\text { Pilar palatino anterior }(n=1)\end{array}$ & $\begin{array}{l}0,3 \times 0,3- \\
1,5 \times 1,5\end{array}$ \\
\hline $\begin{array}{l}\text { Young e } \\
\text { Claman }\end{array}$ & 1967 & 1 & 42 & M & Assoalho bucal & 0,5 (diâmetro) \\
\hline Knapp & 1970 & 13 & & & $\begin{array}{c}\text { Assoalho bucal }(n=7) \\
\text { Palato mole }(n=4) \\
\text { Superfície ventral da língua }(n=2)\end{array}$ & \\
\hline $\begin{array}{l}\text { Acevedo e } \\
\text { Nelson }\end{array}$ & 1971 & 9 & $20-46$ & $9 M$ & Assoalho bucal $(n=9)$ & $\begin{array}{c}0,3 \times 0,2- \\
0,8 \times 0,4\end{array}$ \\
\hline Merchant & 1972 & 1 & 21 & $M$ & Assoalho bucal & 0,3 (diâmetro) \\
\hline $\begin{array}{l}\text { Giunta e } \\
\text { Cataldo }\end{array}$ & 1973 & 21 & $7-65$ & $\begin{array}{l}9 \mathrm{M} \\
12 \mathrm{~F}\end{array}$ & $\begin{array}{l}\text { Assoalho bucal }(n=17) \\
\text { Palato mole }(n=2) \\
\text { Vestíbulo bucal }(n=1) \\
\text { Região retromolar }(n=1)\end{array}$ & $\begin{array}{l}0,3 \times 0,2- \\
1,5 \times 1,5\end{array}$ \\
\hline $\begin{array}{l}\text { Hasegawa } \\
\text { et al. }\end{array}$ & 1974 & 2 & $19-27$ & $\begin{array}{l}1 \mathrm{M} \\
1 \mathrm{~F}\end{array}$ & $\begin{array}{c}\text { Assoalho bucal } \\
\text { Superfície ventral da língua }\end{array}$ & \\
\hline $\begin{array}{l}\text { Sugihara } \\
\text { et al. }\end{array}$ & 1977 & 1 & 41 & $\mathrm{~F}$ & Superfície ventral da língua & $0,6 \times 0,4$ \\
\hline $\begin{array}{l}\text { Buchner e } \\
\text { Hansen }\end{array}$ & 1980 & 38 & $14-81$ & $\begin{array}{l}23 M \\
15 F\end{array}$ & $\begin{array}{c}\text { Assoalho bucal }(n=19) \\
\text { Superfície ventral da língua }(n=7) \\
\text { Superfície lateral da língua }(n=7) \\
\text { Palato mole }(n=2) \\
\text { Pilar palatino anterior }(n=2) \\
\text { Região retromolar }(n=1)\end{array}$ & $\begin{array}{c}0,1-1 \\
\text { (diâmetro) }\end{array}$ \\
\hline $\begin{array}{l}\text { Sakoda } \\
\text { et al. }\end{array}$ & 1983 & 1 & 19 & $\mathrm{~F}$ & Superfície ventral da língua & 0,5 (diâmetro) \\
\hline $\begin{array}{l}\text { Kumara } \\
\text { et al. }\end{array}$ & 1995 & 1 & 29 & M & Assoalho bucal & $0,5 \times 1,5$ \\
\hline Ahn et al. & 1996 & 1 & 56 & $\mathrm{~F}$ & Assoalho bucal & $1 \times 1$ \\
\hline Flaitz & 2000 & 1 & 4 & $M$ & Superfície ventral da língua & 1 (diâmetro) \\
\hline $\begin{array}{c}\text { Flaitz e } \\
\text { Davis }\end{array}$ & 2004 & 1 & 72 & M & Superfície lateral da língua & 0,5 (diâmetro) \\
\hline $\begin{array}{l}\text { Epivatianos } \\
\text { et al. }\end{array}$ & 2005 & 1 & 27 & M & Assoalho bucal & 0,6 (diâmetro) \\
\hline
\end{tabular}

M: masculino; F: feminino; $\mathrm{n}=$ número de casos. 
Distribuição dos 119 casos de cisto linfoepitelial oral apresentados na literatura, de acordo com a faixa etária Tabela 2 dos pacientes

$\begin{array}{ccc}\text { Faixa etária } & \text { Frequência } & \text { Porcentagem } \\ 0-9 & 2 & 1,9 \% \\ 10-19 & 12 & 11,8 \% \\ 20-29 & 32 & 31,4 \% \\ 30-39 & 18 & 17,7 \% \\ 40-49 & 16 & 15,7 \% \\ 50-59 & 15 & 14,7 \% \\ 60-69 & 2 & 1,9 \% \\ 70-79 & 4 & 3,9 \% \\ 80-89 & 1 & 0,9 \% \\ \text { Total }^{*} & 102 & 100 \%\end{array}$

*A informação relativa à idade não estava disponível em 17 casos.

sexo, disponível em 106 dos 119 casos relatados na literatura (Tabela 1), revelou 68 casos $(64,2 \%)$ em homens e 38 casos $(35,8 \%)$ em mulheres, determinando uma proporção homem:mulher de 1,8:1. Sobre esse acometimento preferencial do sexo masculino, três dos quatro casos ora apresentados foram diagnosticados em mulheres.

Geralmente, os cistos linfoepiteliais são identificados em áreas da cavidade bucal que apresentam agregados linfoides ${ }^{(8,12,13,15)}$. A análise dos 119 casos relatados na literatura revelou o assoalho bucal como o sítio mais comum para essas lesões $(63,9 \%)$, seguido das superfícies lateral $(13,5 \%)$ e ventral $(10,9 \%)$ da língua. Localizações afetadas com menor frequência incluíram: palato mole $(6,7 \%)$, pilar palatino anterior $(2,5 \%)$, região retromolar $(1,7 \%)$ e vestíbulo bucal $(0,8 \%)$ (Tabela 3). Com relação aos casos reportados no presente estudo, dois estavam localizados na superfície ventral da língua, um em assoalho bucal e um em orofaringe. Tais achados corroboram o acometimento preferencial de áreas de cavidade bucal que exibem agregados linfoides.

Clinicamente, o cisto linfoepitelial oral se apresenta como um nódulo móvel, assintomático, com coloração que varia do róseo ao amarelado ${ }^{(3,4,7-9,15)}$. Em geral, as lesões são pequenas, apresentando menos de $1 \mathrm{~cm}$ de diâmetro ${ }^{(2,4,7-9,11,14,17)}$, e as características clínicas dos casos reportados no presente estudo corroboram essas afirmações. Raros casos podem atingir $2 \mathrm{~cm}$ de diâmetro(18). O tempo de evolução reportado na literatura varia de 2 meses a 10 anos ${ }^{(1,4)}$. Em virtude do pequeno tamanho e da ausência de sintomatologia, muitas vezes o paciente desconhece a existência da lesão(4), fato que difi-
Distribuição dos 119 casos de cisto linfoepitelial oral apresentados na literatura, de acordo com a localização

Tabela 3 anatômica

\begin{tabular}{ccc}
\hline Localização anatômica & Frequência & Porcentagem \\
Assoalho bucal & 76 & $63,9 \%$ \\
$\begin{array}{c}\text { Superfície lateral } \\
\text { da língua }\end{array}$ & 16 & $13,5 \%$ \\
$\begin{array}{c}\text { Superfície ventral } \\
\text { da língua }\end{array}$ & 13 & $10,9 \%$ \\
Palato mole & 8 & $6,7 \%$ \\
Pilar palatino anterior & 3 & $2,5 \%$ \\
Região retromolar & 2 & $1,7 \%$ \\
Vestíbulo bucal & 1 & $0,8 \%$ \\
Total & 119 & $100 \%$ \\
\hline
\end{tabular}

culta a interpretação do tempo de evolução reportado. Em consonância com a assertiva anterior, informação sobre o tempo de evolução foi reportada em apenas um dos casos ora apresentados.

Histologicamente, os cistos linfoepiteliais orais demonstram cavidade cística revestida por epitélio pavimentoso estratificado, com padrão de maturação que pode variar de não ceratinizado a ortoceratinizado ${ }^{(3,13)}$. Raramente as lesões podem apresentar revestimento epitelial do tipo pseudoestratificado( ${ }^{(4)}$, bem como ocasionais células mucosas em meio ao revestimento epitelial ${ }^{(4,9)}$. O lúmen cístico exibe quantidade variável de células epiteliais descamadas $\mathrm{e}$ células inflamatórias $(1,3,4,9)$, e a interface epitélio-conjuntivo se apresenta plana ${ }^{(1,3,4,7-9,15)}$. Embora as características histopatológicas gerais dos casos ora reportados corroborem as descritas na literatura, nenhum dos espécimes avaliados exibiu células mucosas ou revestimento epitelial do tipo pseudoestratificado. À semelhança de diversos outros relatos na literatura ${ }^{(1,3,4,7-9,15,19)}$, nos casos ora apresentados, constatou-se predomínio do padrão de maturação paraceratinizado no epitélio cístico.

A cápsula fibrosa demonstra intenso infiltrado linfocítico, que pode circunscrever completa ou parcialmente o revestimento epitelial ${ }^{(4,9)}$ e, em geral, não se estende aos tecidos circunvizinhos ${ }^{(3,9)}$. Coerentemente, nenhum dos casos ora apresentados revelou extensão do infiltrado linfocítico aos tecidos adjacentes. Embora Buchner e Hansen ${ }^{(4)}$ e Giunta e Cataldo ${ }^{(9)}$ reportem que a circunscrição completa do revestimento epitelial pelo infiltrado 
linfocítico constitua o padrão mais comum para os cistos linfoepiteliais orais, três dos quatro casos ora relatados demonstraram circunscrição parcial do revestimento epitelial. Centros germinativos, como os identificados em dois casos reportados no presente estudo, são observados na maioria dos cistos linfoepiteliais orais, em maior ou menor extensão ${ }^{(1,3,4,7,9,15,19)}$. Raramente, os cistos linfoepiteliais orais podem se apresentar em associação a outras lesões císticas, como o cisto epidermoide ${ }^{(6)}$.

A excisão cirúrgica conservadora é o tratamento de escolha para o cisto linfoepitelial oral(3,7-9,15). Entretanto, é reportado que lesões com características típicas o bastante para serem diagnosticadas clinicamente e que não determinam qualquer desconforto ao paciente não necessitariam ser submetidas à biópsia(15), sendo sugerida apenas a pro- servação ${ }^{(8)}$. Não há relatos de transformação neoplásica ou recorrência após a excisão cirúrgica ${ }^{(3,7-9,15)}$.

\section{Conclusão}

A análise conjunta dos casos apresentados neste trabaIho e de outros 119 casos relatados na literatura revela que os cistos linfoepiteliais orais exibem predileção pelo sexo masculino, com ápice de incidência na terceira década de vida. Tipicamente, essas lesões se apresentam como pequenos nódulos assintomáticos, localizados no assoalho bucal. Histologicamente, a maioria dos casos revela epitélio cístico com padrão de maturação paraceratinizado e exibe centros germinativos na cápsula fibrosa.

\section{Referências}

1. ACEVEDO, A.; NELSON, J. F. Lymphoepithelial cysts of the oral cavity. Oral Surg, v. 31, p. 632-5, 1971.

2. AHN, S. K. et al. Lymphoepithelial cyst associated with epithelial inclusion cyst. Am J Dermatopathol, v. 18, p. 424-6, 1996.

3. BHASKAR, S. N. Lymphoepithelial cysts of the oral cavity: report of twenty-four cases. Oral Surg Oral Med Oral Pathol, v. 21, p. 120-8, 1966.

4. BUCHNER, A.; HANSEN, L. S. Lymphoepithelial cysts of the oral cavity: a clinicopathologic study of thirty-eight cases. Oral Surg, v. 50, p. 441-9, 1980.

5. CALMAN, H. J. Sublingual branchiogenic cyst. Oral Surg, v. 16, p. 333-8, 1963.

6. EPIVATIANOS, A.; ZARABOUKAS, T.; ANTONIADES, D. Coexistence of lymphoepithelial and dermoid cysts on the floor of the mouth: report of a case. Oral Dis, v. 11, p. 330-3, 2005.

7. FLAITZ, C. M. Oral lymphoepithelial cyst in a young child. Pediatr Dent, v. 22, p. 422-3, 2000.

8. FLAITZ, C. M.; DAVIS, S. E. Oral and maxillofacial pathology case of the month: oral lymphoepithelial cyst. Tex Dent J, v. 121, p. 630-1, 2004.

9. GIUNTA, J.; CATALDO, E. Lymphoepithelial cysts of the oral mucosa. Oral Surg, v. 35, p. 77-84, 1973.

10. GOLD, C. Branchial cleft cyst located in the floor of the mouth. Oral Surg, v. 15, p. 1118-20, 1962.

11. HASEGAWA, K. et al. Lymphoepithelial cysts of the oral cavity: report of 2 cases. J Dent Osaka Univ, v. 20, p. 59-63, 1974.

12. KNAPP, M. J. Pathology of oral tonsils. Oral Surg, v. 29, p. 295-304, 1970.

13. KUMARA, G. R.; GILLGRASS, T. J.; BRIDGMAN, J. B. A lymphoepithelial cyst (branchial cyst) in the floor of the mouth. N Z Dent J, v. 91, p. 14-5, 1995.
15. MERCHANT, N. E. Lymphoepithelial cyst of the floor of the mouth: a case report. Br Dent J, v. 132, p. 271-2, 1972.

16. NEVILLE, B. W. et al. Patologia oral \& maxilofacial. 2. ed. Rio de Janeiro: Guanabara Koogan, 2004. p.35-6.

17. SAKODA, S.; KODAMA, Y.; SHIBA, R. Lymphoepithelial cyst of oral cavity: report of a case and review of the literature. Int J Oral Surg, v. 12, p. 127-31, 1983.

18. SUGIHARA, K. et al. Lymphoepithelial cyst on the ventral surface of the tongue: report of a case. Japan J Oral Surg, v. 23, p. 643-8, 1977.

19. VICKERS, R. A.; GORLIN, R. J.; SMART, E. A. Lymphoepithelial lesion of the oral cavity: report of four cases. Oral Surg, v. 16, p. 1214-22, 1963.

20. YOUNG, W. G.; CLAMAN, S. M. A lymphoepithelial cyst of the oral cavity. Oral Surg Oral Med Oral Pathol, v. 23, p. 62-70, 1967. 